\title{
The Research of High-speed Rail Bridge Construction Deformation Prediction System Based on Genetic Neural Network
}

\author{
Cheng-Xue $\mathrm{YU}^{1, \mathrm{a}}$, Mian TANG ${ }^{2}$, Yu-Cai NING, Xu-Hui HE \\ ${ }^{1}$ College of Civil Engineering, Central South University Changsha 410075 China \\ ${ }^{2}$ Hangzhou Railway Design Institute Co., Ltd., Hangzhou 310016, China \\ a578144655@qq.com
}

Keywords: Construction Monitoring, Neural Network, Continuous Beam Bridge.

\begin{abstract}
Based on the structural feature of high speed railway bridge, one space finite element model is established for the construction of the influence factors of the bridge deformation sensitivity analysis. Using adaptive genetic algorithm and neural network technology, taking the deformation of the bridge sample error minimizing as the objective function to get the new BP neural network after the neural network model weights and thresholds optimized. And compile eformation intelligent forecasting system based on MATLAB platform. Taking the cantilever construction of Shanghai-Kunming high-speed rail a continuous beam of measured data compared with the predicted results of experimental data, the results shows that the method is of high accuracy, good feasibility, provided reference for high precision linear intelligent control to similar Bridges.
\end{abstract}

\section{Introduction}

As the high speed of High-speed railway, in order to meet running safety and passengers' comfort requirements and avoiding the resonance and the dynamic response is too big, the high-speed railway Bridges is very strict to the requirement of stiffness and deformation especially for the ballastless track as its elevation adjustment is very limited .The current Code for design of high speed railway (TB10020-2009) regulation of beam body vertical deformation limit applies only to small and medium span of bridge structure.

Our country has formed the standardized design for the less than $100 \mathrm{~m}$ span prestressed concrete bridge in high speed railway that usually using the cantilever pouring construction. The method is setting temporary consolidation at the top of the pier at begin and the system transferred after closure, that needs the construction of linear control accuracy within $5 \mathrm{~mm}$. So it is very important to carry out strict linear monitoring on the bridge during construction, and take the vertical deformation as the primary monitoring object to ensure the successful closure and linear smoother. The ways commonly used in the construction control including open-loop control, closed-loop control and adaptive control and so on ${ }^{\mathbf{6} 6 \mathbf{I}}$.Due to load changes, structure performance, construction environment and other factors that affecting the uncertainty of bridge deformation cannot be determined, the construction condition of each bridge is different, that puts forward higher requirements on the remote intelligent construction monitoring. It shows that the neural network who has a superior nonlinear mapping ability and the global search ability applied in bridge construction monitoring is feasible.

This paper selecting the Liling super-large bridge and Ping river bridge and other several continu ous beam bridges on shanghai-kunming high-speed rail way whose span including ( $48+2 \mathrm{x}$ $80+48) \mathrm{m},(60+100+60 \mathrm{~m}), \mathrm{m}(40+72+40),(48+80+48) \mathrm{m}$ to study the measured data. This paper analyses the factors influencing bridge deformation. In this paper, simulation analysis was carried out on the bridge structure construction process the deformation and internal force of the structure under calculation, and develop its deformation prediction platform and by using the actual monitoring data to adjust the actual status of the structure of the bridge, this paper provide certain reference basis for the research of large span bridge deformation limit value and remote intelligent monitoring system of similar bridges. 


\section{Sensitivity Analysis of Bridge Deformation Factors}

There are many factors that can influence of bridge construction process, such as the weight of bridge, construction live load, displacement of foundation, temperature change, loss of prestress[3]This paper selects $(48+80+48) \mathrm{m}$ prestressed concrete three span one coupling variable cross section continuous beam bridge as an example, the single box beam fulcrum beam 6.65 meters high, across the centre sill height of $3.85 \mathrm{~m}$. This paper used the finite element software Midas to do the analysis of bridge structure, to simulate the whole construction process, and to do the research of each construction stage of girder internal force and deflection.



Fig. 1 Schematic Diagram of Box Girder Section

\section{The Error Analysis of Continuous Girder Bridge Structure}

There are many factors that caused the bridge structure theory state and actual state different. The factors can be summarized into four categories by the way of the classification of error sources , such as the load change, the difference of structure performance, environment influence and distortion calculation model[5] .After qualitative analysis was carried out on the structural error sources, this paper do the quantitative analysis, it help making sure structure about the sensitivity of the error effects. The specific scope of the parameters and the parameters showed in table 1

Tab. 1 The Main Parameters of the Structure

\begin{tabular}{cccc}
\hline main parameters & benchmark status & Case one & Case two \\
\hline weight & Design value & $5 \%$ & $10 \%$ \\
elastic modulus & $\mathrm{E}=3.45 \times 104 \mathrm{MPa}$ & $5 \%$ & $10 \%$ \\
prestressed & Design value & $5 \%$ & $10 \%$ \\
temperature & Design value & $5^{\circ} \mathrm{C}$ & $10^{\circ} \mathrm{C}$ \\
construction load & Design value & $5 \%$ & $10 \%$ \\
\hline
\end{tabular}

(1) The effect on the behavior into the bridge structure while the main girder's weight changed

The weight values increased by $5 \%$, reduce $5 \%$, increased by $10 \%$ and reduce $10 \%$.

As shown in figure 2 , in the four cases of the weight values increased by $5 \%$, reduce $5 \%$, increased by $10 \%$ and reduce $10 \%$, the deflection of the segment in front of the mid-span closure segment value respectively is $-3.53 \mathrm{~mm},-4.06 \mathrm{~mm},-2.56 \mathrm{~mm},-2.05 \mathrm{~mm}$, the change rate of $16 \%$, $33 \%, 16 \%, 33 \%$, the relative change in maximum.

(2) The concrete elastic modulus changes impact on the behavior of bridge structure

As shown in figure 3 , in the three cases of the elastic modulus values increased by $5 \%$, reduce $5 \%$, and reduce $10 \%$, the deflection of the segment in front of the mid-span closure segment value respectively is $-2.87 \mathrm{~mm},-2.67 \mathrm{~mm},-3.13 \mathrm{~mm}$, the change rate of $7 \%, 9 \%, 17 \%$. 
(3) The effect on the behavior of bridge structure as the loss of prestress

This paper considers the loss by $5 \%, 10 \%$ and $15 \%$, the results are shown in figure 5 .
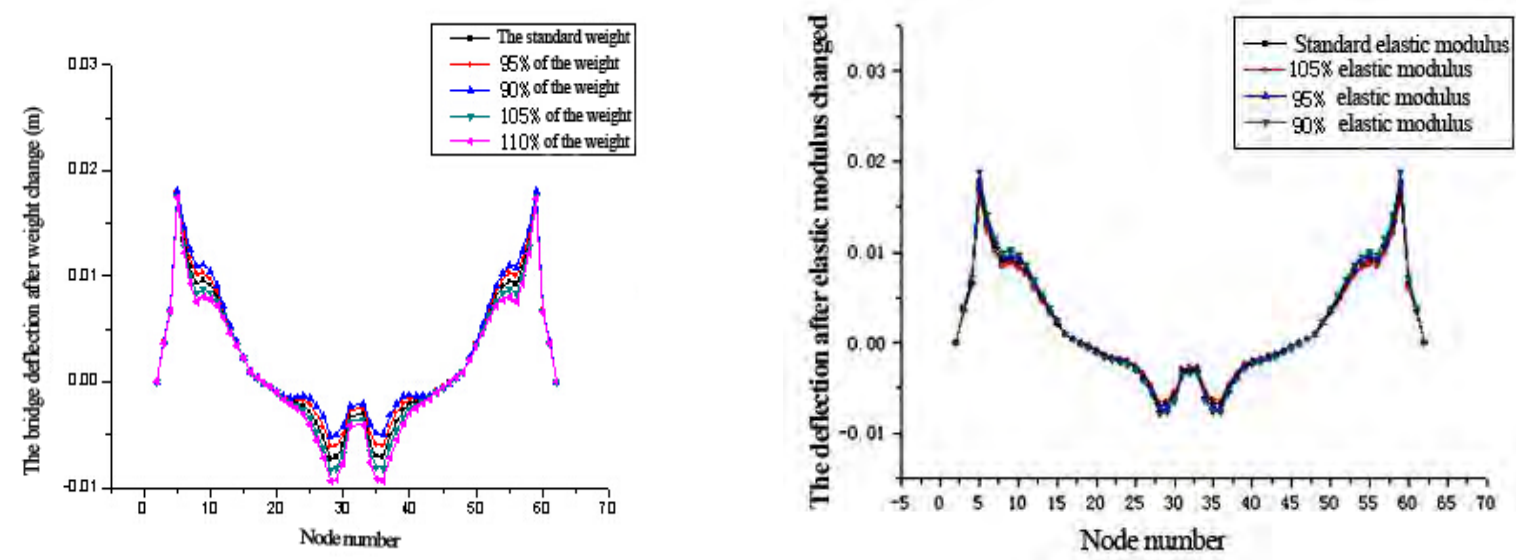

Fig. 2 Effect of Weight Change on the Bridge Alignment Fig. 3 Effect of Elastic Modulus of Concrete
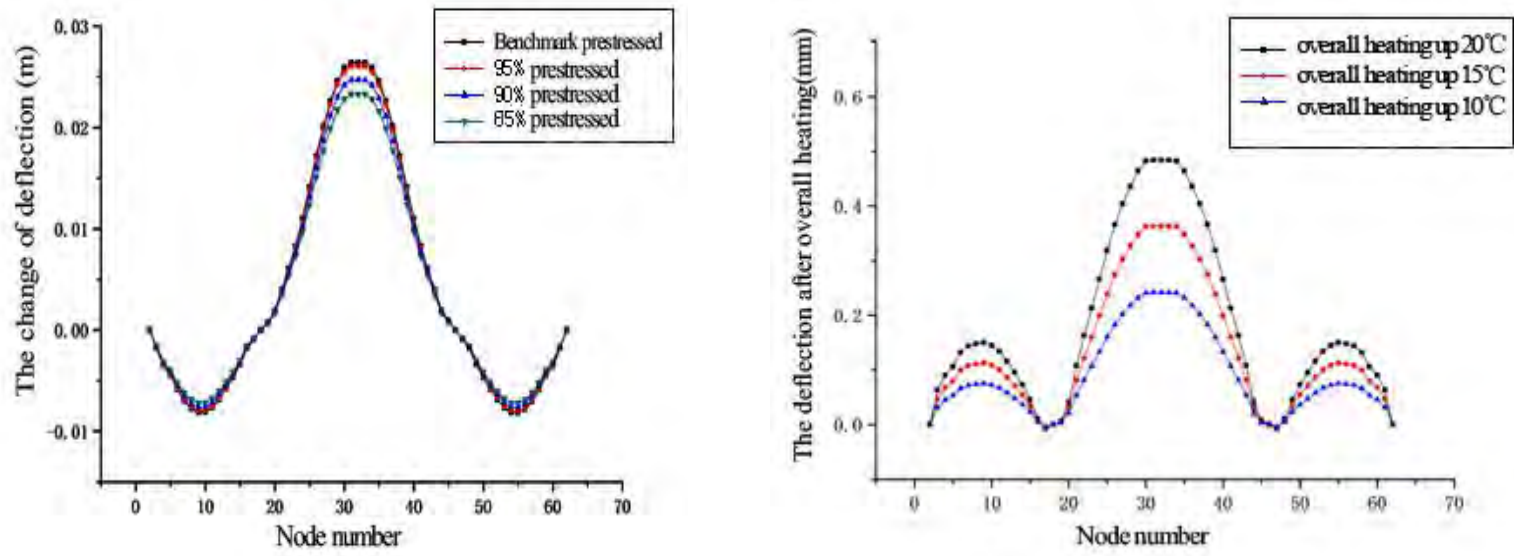

Fig. 4 Effect of Prestress Loss

Fig. 5 Effect of the Overall Heating on the Bridge Alignment

As shown in figure 4 , in the three cases of the prestress loss values reduce $5 \%$, reduce $10 \%$ and reduce $15 \%$, the camber of mid-span value respectively is $26.4 \mathrm{~mm}, 26.1 \mathrm{~mm}, 24.7 \mathrm{~mm}$, the change rate of $1.2 \%, 6.5 \%, 11.8 \%$.

(4)The effect on the behavior of bridge structure as the overall heating or cooling

Effect on bridge linear is opposite symmetrical when overall heating or cooling, so this paper consider the overall heating respectively $10^{\circ} \mathrm{C}, 15^{\circ} \mathrm{C}, 20^{\circ} \mathrm{C}$ three conditions to calculate the overall warming effect on the bridge line, the results of the analysis as shown in figure 5

As shown in figure 5, when the overall heating on complete bridge, the bridge deck heating up $20 \mathrm{C}, 15 \mathrm{C}, 10 \mathrm{C}$, the maximum deflection in the mid-span value is respectively $0.484 \mathrm{~mm}, 0.363 \mathrm{~mm}, 0.242 \mathrm{~mm}$, the deflection value is linear growth. the deflection caused by temperature is less than $1 \mathrm{~mm}$, it has little effect when overall heating on complete bridge

(5)The effect on the behavior of bridge structure as the temperature gradient change

This paper considers the bridge deck heating up $5 \mathbb{C}$ or $10 \mathbb{C}$, the results of the analysis is shown in figure 7 and figure 8.

As shown in figure 6, when the temperature gradient changed on completed bridge, the bridge deck heating up $10 \mathrm{C}$, the maximum deflection in the mid-span cross is $5.49 \mathrm{~mm}$, the bridge deck heating up $5^{\circ} \mathrm{C}$, the maximum deflection in the mid-span cross is $2.75 \mathrm{~mm}$, the deflection value is linear growth.

As shown in figure 7, when the temperature gradient changed on cantilever construction maximum cantilever state, the bridge deck heating up $10 \mathbb{C}$, the maximum deflection in the 
mid-span cross is $11.6 \mathrm{~mm}$, the bridge deck heating up $5^{\circ} \mathrm{C}$, the maximum deflection in the mid-span cross is $5.8 \mathrm{~mm}$, the deflection value is linear growth.
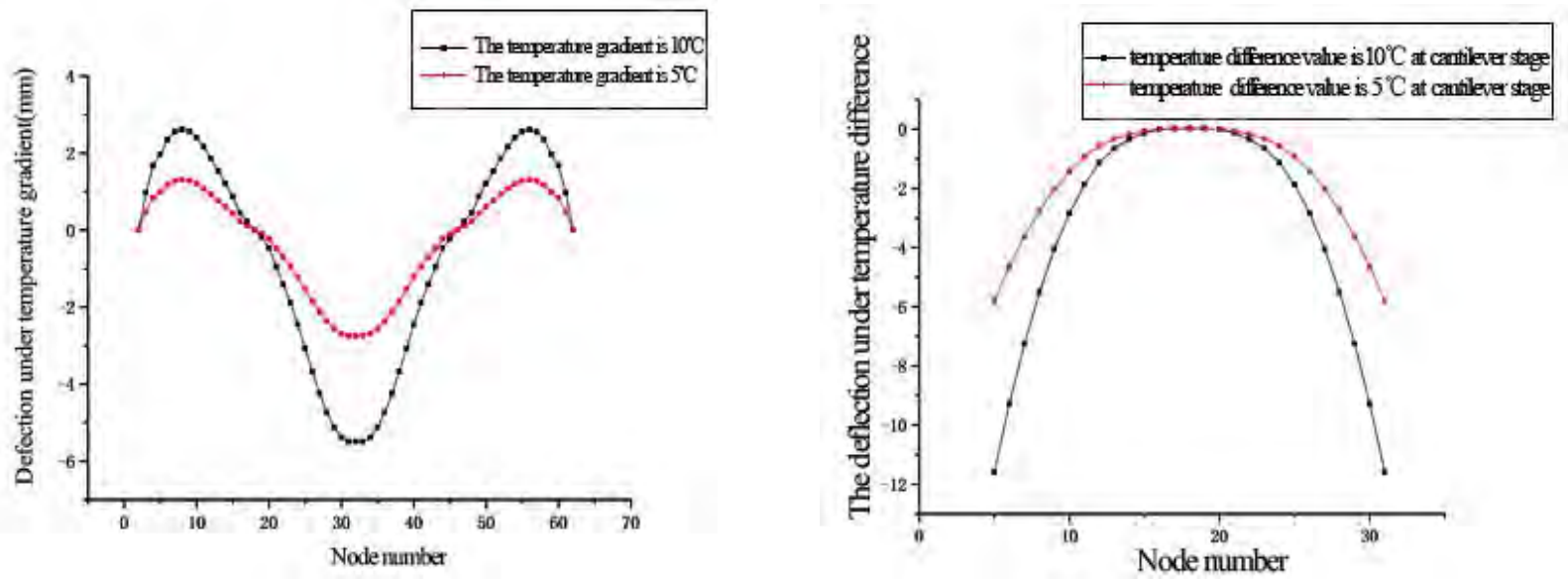

Fig.6 Effect of Temperature Gradient Change Fig.7 Effect of Temperature Gradient Change on Cantilever Construction Stage

\section{The Development of Deformation Intelligent Forecasting System}

Using the MATLAB neural network toolbox and the genetic algorithm module, this paper has formed a BP neural network to merge and predict the deformation of bridge in construction stage.this paper chooses adaptive genetic algorithm. This algorithm using real number encoding, taking neural network predicting output and desired output error absolute value as the fitness function, using the roulette method for choosing operation, using the real crossing method for crossover operation and using random selection position for mutation operation .Real number coding is better than that of binary code on the convergence speed, the form as follows

$$
\mathrm{W}=\left\{W_{i}=\left\{\omega_{1, i}, v_{2, i}, \theta_{1, i}, \gamma_{2, i}\right\}\right.
$$

$\mathrm{i}=1-\mathrm{P}, \mathrm{P}$ for the population size, $\omega_{1, i}$ for the connection weights between input layer to hidden layer, $v_{2, i}$ for the corresponding threshold, $\theta_{1, i}$ for the connection weights between hidden layer to output layer, ${ }_{2, i}$ for the corresponding threshold.

Moderate function uses the training sample error of the mean square error, and think of the fitness of the great error in the small, concrete manifestation is:

$$
\begin{aligned}
& \operatorname{se}\left(W_{i}\right)=\frac{1}{N \times M} \sum_{k=1}^{N} \sum_{j=1}^{M}\left(O_{j}(k)-T_{j}(k)\right)^{2} \\
& f i t\left(W_{i}\right)=\frac{1}{\operatorname{se}\left(W_{i}\right)}
\end{aligned}
$$

$\mathrm{W}$ for the individuals in the population, $\mathrm{N}$ for the number of network input samples, $\mathrm{M}$ for output layer nodes. oj, $\mathrm{T} j$ for the actual output and desired output of the node $\mathrm{j}$

According to above analysis, choosing the girder weight, the effective prestressed the measuring temperature, and the three segment deflection in front of the construction segment as the network input layer node parameters, according to the commonly used formula between hidden layer and input layer between to calculate the numbers of hidden layers ,here is the choice:

$$
\mathrm{m}=2 \mathrm{n}+1
$$




\section{The Application of BP Neural Network in the Construction Control}

The construction monitoring data measured on the field of multiple continuous beam bridges like Lilin Bridge and Pingshuihe Bridge on the Hangzhou-changsha part of Hu-kun HSR is studied to predict the deflection on the $9 \#$ segment of a continuous beam whose main span is 80 meters. Parameters in genetic algorithm are set as follows: the convergent error of the network is 10E-5, the number of population is 10 , the maximum evolutional generation is 50 , the selective probabilities are decided by individual fitness and the crossover probability and mutation probability are 0.3 and 0.1 respectively, the value of weights and thresholds of neural network which are optimized by genetic operation can be seen in [8]. The estimate of the weight of the main girder is $105 \%$, the effective prestressing is equal to the designed value, the practical temperature gradient of temperature field is $5^{\circ} \mathrm{C}$, the temperature modified deflections of the three segments in front of $9 \#$ segment are $5.2 \mathrm{~mm}, 8.0 \mathrm{~mm}, 11.5 \mathrm{~mm}$ respectively. The deflections of the beam on $9 \#$ segment after concreting are predicted based on the practical data, and the results are shown in figure $9 \sim 10$.

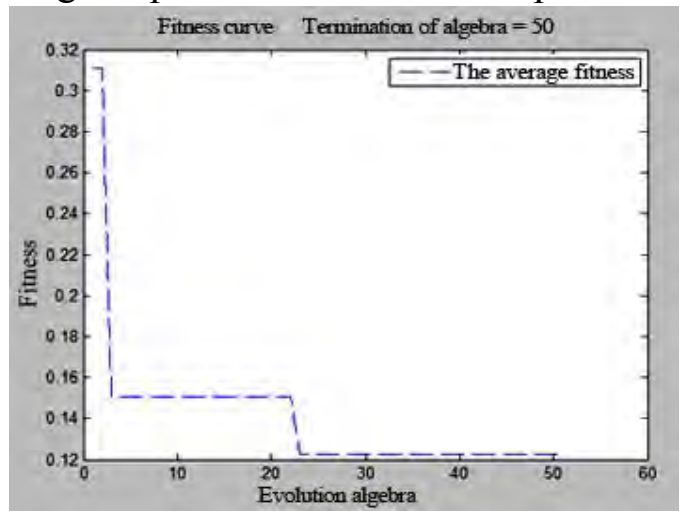

Fig. 8 Genetic Network Fitness Curve



Fig.9 Error of Network Prediction

Tab. 2 Top Elevation of the Girder after the Closure

\begin{tabular}{|c|c|c|c|c|c|c|}
\hline \multirow{2}{*}{$\begin{array}{c}\text { Beam } \\
\text { section }\end{array}$} & \multicolumn{3}{|c|}{$\begin{array}{c}\text { Theory values of top } \\
\text { beam elevation (m) }\end{array}$} & \multicolumn{2}{|c|}{$\begin{array}{c}\text { Measured values of top beam } \\
\text { elevation }\end{array}$} & \multirow{2}{*}{$\begin{array}{c}\text { Solid - } \\
\text { Richard }\end{array}$} \\
\cline { 2 - 6 } & left side & Right side & $\begin{array}{c}\text { left } \\
\text { side }\end{array}$ & Right side & The mean & deviation(\%) \\
\hline $\begin{array}{c}\text { Cast-in-situ } \\
\text { segment }\end{array}$ & 88.499 & 84.473 & 88.495 & 88.495 & 88.497 & -0.2 \\
\hline $10^{\#}$ block & 88.502 & 84.464 & 88.499 & 88.501 & 88.500 & -0.2 \\
\hline $9^{\#}$ block & 88.497 & 84.398 & 88.493 & 88.485 & 88.489 & -0.8 \\
\hline $8^{\#}$ block & 88.491 & 84.314 & 88.476 & 88.472 & 88.474 & -1.7 \\
\hline $7^{\#}$ block & 88.482 & 84.262 & 88.464 & 88.466 & 88.465 & -1.7 \\
\hline $6^{\#}$ block & 88.477 & 84.238 & 88.459 & 88.459 & 88.459 & -1.8 \\
\hline $5^{\#}$ block & 88.469 & 84.237 & 88.457 & 88.457 & 88.457 & -1.2 \\
\hline $4^{\#}$ block & 88.459 & 84.258 & 88.443 & 88.443 & 88.443 & -1.6 \\
\hline $3^{\#}$ block & 88.448 & 84.300 & 88.440 & 88.453 & 88.447 & -0.2 \\
\hline $2^{\#}$ block & 88.439 & 84.376 & 88.424 & 88.440 & 88.432 & -0.7 \\
\hline $1^{\#}$ block & 88.431 & 84.420 & 88.443 & 88.437 & 88.440 & 0.9 \\
\hline
\end{tabular}

As shown in figure 9, the relative prediction error of $9^{\#}$ section is $18 \%$, the measured deflection value is $13.0 \mathrm{~mm}$, the prediction of the deflection value is $15.3 \mathrm{~mm}$, the absolute error is $2.3 \mathrm{~mm}$, the absolute error precision can satisfy the required accuracy for engineering applications. Results show that the deformation of the bridge based on the genetic neural network real-time forecast method is effective.

Taking the Ping river above six factors in Mid-span closure segments between \# 16 pier and 19 \# pier as input parameters to predict beam top elevation and compared with the measured elevation, 
the results are shown in table2.

\section{Conclusion}

Influence level of different factors affecting the deflection of continuous bridges of high speed railway in construction has been analyzed with a spatial finite element model. An intelligent forecasting system based on the optimized network structure of genetic algorithm has been developed with the help of MATLAB, thus the deflection in construction of a continuous beam in high speed railway of which the mail span is $80 \mathrm{~m}$ has been predicted and then compared with the measured values. Conclusions are listed below.

(1) Deflection in construction is influenced by the factors of gravity, construction load, pre-stress, concrete shrinkage and creep, temperature etc.

(2) Weight change of beam segment, loss of pre-stress and temperature variation are three major influence effects on beam deflection in construction.

(3) Programmed with MATLAB, the forecasting system based on genetic algorithm and artificial neural networks is operated with good stability and convenience, and can provide excellent predictions.

(4) The system can provide reference to linear remote supervision of bridge with high precision.

\section{References}

[1]Hasancebi.O, Dumlupinar.T. Linear and nonlinear model updating of reinforced concrete T-beam bridges using artificial neural networks[J]. Computers \& Structures, 2013,119(4), pp.

[2]Zeng Zhigang, Wang Jun. Advances in Neural Network Research and Applications[M].Mechanical Industry Press Mechanical Industry, 2010,578-586.

[3]Jiang Zhonggui, Sheng Liming. Technology and Suggestions on the Bridges on Passenger Dedicated Line [J].Journal Of Railway Engineering Society, 2008(1):1-5.

[4]Huang Kan, Liu Baochen. Intelligent back-analysis of tunnel surrounding rock displacement based on genetic algorithm and neural network [J]. Journal Of Central South University (Science And Technology), 2011, 42(1):213-219.

[5]Yuan Xiaofang, Wang Yaonan. A hybrid learning algorithm for RBF neural networks based on support vector machines and BP algorithms[J]. Journal Of HUNAN University (Natural Sciences), 2005, 32(2):88-92.

[6]Wu Dahong. Study on the structural health monitoring system of bridges based on artificial neural network and genetic algorithms [D]. Southwest Jiaotong University. 2003.

[7]XI Hui-feng, TANG Li-qun. Optimization of Bridges' Parameters Based on BP Neural Network and Genetic Algorithm[J]. Journal of Zhongshan University(Natural Sciences), 2008,47(s):46-49.

[8]Ning Yucai. Deformation Prediction and Control for High-speed Bridge based on Genetic Neural Network [D]. Central South University. 2013. 